\title{
Molecular typing methods for Neisseria meningitidis
}

\author{
DAVIS E. YAKUBU, FARIBORZ J. R. ABADI and T. HUGH PENNINGTON \\ Department of Medical Microbiology, Aberdeen University Medical School, Foresterhill, Aberdeen AB25 $2 Z D$
}

\begin{abstract}
Neisseria meningitidis is an important pathogen because it causes life-threatening infections. The rapid course of meningococcal disease and the capacity of some serogroups to cause large-scale epidemics necessitates the use of sensitive, reliable and rapid typing methods to characterise strains. Molecular typing techniques for $N$. meningitidis are used for epidemiological purposes to investigate outbreaks and the spread of organisms and to examine the population genetic structure of the organism to understand better its variation and evolution. Many investigators have employed molecular typing methods and shown that meningococcal disease is associated with a variety of different epidemiological patterns. The choice of a typing method is dependent upon the epidemiological questions to be answered and on the population genetics of the organism under investigation. With highly clonal populations comprising independent non-recombining lineages such as serogroup A meningococci, ribotyping, multilocus enzyme electrophoresis (MLEE), pulsed-field gel electrophoresis (PFGE), multilocus sequence typing (MLST), PCR with arbitrary primers (RAPD) or with other gene-based primers each provides a constant measure of the relationship between strains. A more restricted portfolio of molecular methods - PFGE, MLEE and MLST - is appropriate for the investigation of less clonal serogroup $B$ and $C$ meningococci from localised outbreaks. If a thorough evaluation of the overall population is sought to determine the relationship between new isolates and members of hyper-endemic clonal complexes then quantitative methods such as MLEE and MLST are necessary. Several PCR-based methods are used for the detection and typing of meningococcal strains, many requiring rigorous standardisation before they can be considered suitable for rapid and reliable differentiation between clones. This review examines strain characterisation by molecular techniques and non-culture-based subtyping of meningococci in clinical specimens. It assesses the importance of these techniques and examines the epidemiological questions that they answer and also their limitations.
\end{abstract}

\section{Introduction}

Neisseria meningitidis is an important cause of morbidity and mortality worldwide $[1,2]$. It causes a broad spectrum of diseases that ranges from transient fever and bacteraemia to fulminant septicaemia and meningitis [3]. Thirteen serogroups are recognised. Only five - A, B, C and to a lesser extent $\mathrm{Y}$ and $\mathrm{W}$ 135 - are clinically important. Satisfactory control of disease by vaccination has not yet been achieved [4].

Received 15 Jan. 1999; revised version accepted 2 June 1999.

Corresponding author: Dr D.E. Yakubu (e-mail: mmb048@) abdn.ac.uk).
Several typing methods that examine isolates for characteristics that permit discrimination below the species level have been devised. Such studies are done to enhance our understanding of meningococcal infections and improve our ability to design novel means of prophylaxis and treatment. Serogrouping based on capsular polysaccharides and serotyping based on outer-membrane proteins (OMPs) and lipo-oligosaccharides (LOSs) [5-8] are simple and relatively widely available. Phenotypic methods of typing $N$. meningitidis are detailed elsewhere [8-10]. However, these phenotypic methods suffer from problems of antigenic variability, inability to subtype all isolates, poor expression or masking of surface antigens and the need to constantly enlarge the reagent panel. Phenotypic characters reflect only a tiny fraction of the coding potential of the organism's genome [11]. 
Sensitive and reproducible molecular typing methods are necessary, not only for epidemiological and population genetic investigations, but also for vaccine-related studies [12]. The population biology of $N$. meningitidis is complex and the rates at which meningococci diversify appear to vary considerably. Thus the choice of a typing method depends upon the question being addressed. The majority of questions relate to the nature of the strains causing meningococcal disease and their relationship to similar diseasecausing isolates obtained within a community, a country, or globally. Meningococcal typing is required to identify outbreaks associated with particular serogroups (as vaccines are serogroup-specific), to demonstrate epidemiological links between cases or between cases and carriers in an outbreak, to monitor the changing epidemiology of disease and to evaluate new vaccines. For molecular typing, three major macromolecules form the basis of discrimination, lipopolysaccharide and fatty acid, proteins or nucleic acid [13]. The majority of molecular typing methods for $N$. meningitidis are either protein- or nucleic acid-based. Molecular typing methods can be highly reproducible and very accurate in determining relatedness of microbial strains and are applicable to all strains.

\section{Definitions}

Clone - one strain and its closely related variants, i.e., strains that are so similar that they are considered to be derived from a common parent.

Microevolution - the accumulation of genetic changes at one or a few loci in clonally related bacteria.

Linkage - the tendency of loci in physical proximity to exhibit co-inheritance of their alleles.

Linkage disequilibrium - allelic association due to close linkage.

Panmictic population structure - those populations in which frequent DNA recombination occurs between strains resulting in a non-clonal population structure.

Epidemiologically related isolates - isolates cultured from patients, fomites or the environment for which there is a demonstrable link in time, place or contact. Such isolates may be derived from a common source. Outbreak strains - isolates of the same species that are both epidemiologically related (e.g., by time, place and common source of infection) and genetically related (i.e., have indistinguishable genotypes).

Endemic strains - isolates that are obtained frequently from infected patients in a particular health care setting or community and which are indistinguishable or closely related to each other by typing methods, but for which no direct or epidemiological linkage can be demonstrated.

Reproducibility - determined by the percentage of strains classified as the same type on repeated testing. Appropriate control strains must be used to ensure reproducibility of typing results.
Typability - the proportion of all existing strains that can be typed by a particular method.

Simpson discrimination index - a method for determining the discriminatory ability of a typing method [14]. It is a numerical index of discrimination based on the probability that two unrelated strains sampled from the test population will be placed into different typing groups.

Genetic diversity - may be expressed as the mean allelic diversity over all loci. If the value approaches one it indicates a high degree of dissimilarity or heterogeneity within the population, whereas values closer to zero indicate a high degree of similarity or homogeneity.

\section{Molecular typing methods}

Traditional typing methods in clinical settings have been based on serogrouping (capsular polysaccharides), serotyping and subtyping (class 1, 2, and 3 OMPs) and sulphonamide resistance [15]. These methods are limited in their usefulness because on a global basis serogroup and, to a lesser extent serotype, correlate poorly with genetic relatedness.

Since the early 1980 s, the electrophoretic variation of cytoplasmic iso-enzymes (and less frequently OMPs) has been used to subdivide meningococci into distinct electrophoretic types (ETs) [16,17]. The use of multilocus enzyme electrophoresis (MLEE) permitted the differentiation of ETs and allowed improved discrimination between strains [16-18]. While some ETs are highly distinct, other ETs that are marginally different have been grouped into 'clones'. Some clones have been repeatedly isolated over many decades from different continents while others have been isolated only rarely and from discrete locations. The versatility and advantages of molecular typing over phenotyping techniques were demonstrated when MLEE was applied to 500 strains of serogroup A meningococci isolated worldwide. The strains were subdivided into subgroups and each subgroup was associated with endemic or epidemic characteristics, or both [19]. Serogroup A subgroup IV-I is endemic in the African meningitis belt, whereas a clone of subgroup III (clone III-I) was responsible for the last pandemic $[19,20]$. MLEE also demonstrated the pandemic spread of clone III-I from early in the 1980s to 1990 [20] and showed how meningococcal infection which began in Asia was carried to Mecca and then to countries throughout the African meningitis belt. Central to epidemiological surveillance of meningococcal infection and public health decisions is the ability to characterise accurately strains responsible for infection at a local level as well as to put them in a global context. None of the methods currently available can achieve this goal in a consistently satisfactory way, as individual methods demonstrate either micro-variations or macro-variations in the genome and not both. 


\section{Principles}

The population genetics of $N$. meningitidis as a species is complex. Lineages vary in the rate at which genetic variation occurs. For serogroup A strains the rate of variation is low and the population structure is clonal, i.e., clones persist for long periods. The population structures of serogroups $\mathrm{B}$ and $\mathrm{C}$ are essentially nonclonal because recombination rates are high. It is noteworthy that serogroups B and C can have 'clones' due to the emergence and spread of transitory hyperendemic isolates that flourish at intervals, but which with time eventually become broken down by recombination [21]. As all genetic differences between individual bacterial cells are related to the primary sequence of their genomic DNA, the most direct method of identifying an individual isolate would be to determine this sequence for the whole genome. This is not currently feasible.

Molecular typing methods achieve discrimination in two different ways. For meningococci, highly variable regions of the genome or individual loci within the bacterial population can be identified and appropriate restriction enzymes or PCR primers chosen. Such typing methods include pulsed-field gel electrophoresis (PFGE), restriction endonuclease analysis (REA), ribotyping, gene-based methods and PCR-based methods. To a varying degree these methods are able to identify the micro-variation that is required to distinguish between strains circulating within a geographical location. In general they are not particularly suitable for long-term or global epidemiology.

The second approach is based on methods that index variations that accumulate very slowly and are likely to be selectively neutral. These methods are suitable for long-term and global epidemiology and include MLEE and multilocus sequence typing (MLST).

\section{Methods that index rapidly evolving variations}

A number of DNA-based typing techniques have been used to determine genetic relatedness among meningococcal isolates. These include genomic restriction endonuclease digestion, either with frequently cutting enzymes [22-25] or with rare-cutting enzymes as used in PFGE $[11,22]$. Several modifications have permitted easy analysis of genomic restriction endonuclease digestion with frequently cutting enzymes and these include the use of 16S RNA probes, i.e., ribotyping [26], and probes for the pilA gene [27] and porA gene [28]. The latter two gene typing methods make use of the PCR. Specific primers are used to amplify these gene sequences and the products are subjected to restriction endonuclease analysis with different enzymes and the restriction endonuclease patterns obtained are compared. These techniques, which index rapidly evolving variations in the meningococcal genome, will be considered in turn to examine their utility and the epidemiological questions that can be answered.

\section{Restriction endonuclease analysis}

Restriction endonuclease analysis (REA) depends on cleavage of genomic DNA by endonucleases at the sites of specific sequences and separation of the resulting fragments by agarose or polyacrylamide gel electrophoresis. In principle, all isolates may be typed by REA. REA of genomic DNA with frequently cutting endonucleases has been used widely for comparison of strains from a large variety of species of microorganisms. Bjorvatn and colleagues [23] were the first to apply this technique to meningococci. They determined the genomic diversity of Scandinavian and African strains of meningococci [23, 24]. Genomic DNA digested with frequently cutting endonucleases usually generates many DNA fragments and the resulting gel patterns are, therefore, difficult to analyse. Computer analysis is necessary to generate dendrograms that provide useful information on the similarity and inter-relationships between gel patterns, and therefore between isolates.

Jordens and Pennington examined 94 isolates of $N$. meningitidis by REA. Digestion of genomic DNA with $B g l$ II, which gave patterns with c. 10 bands [26], subdivided them into 54 groups. When REA with $S t u 1$ was compared with PFGE in the analysis of 34 isolates, there was $71 \%$ agreement in their results and REA showed a lower discriminatory power. With the frequently restricting enzyme $S t u 1$, not all fragments were resolved, as smaller fragments run off the end of the gel. Thus REA patterns did not reflect the complete genomes of the isolates [22]. REA is suitable for typing both the highly clonal serogroup A population [24] and less clonal serogroup C population [22].

\section{PFGE}

Genomic DNA can be digested by rare-cutter restriction endonucleases to generate a limited number $(10-$ 20) of high mol. wt restriction fragments. Whereas standard electrophoresis can only separate DNA molecules that are $<20 \mathrm{~kb}$, PFGE can separate DNA molecules as large as $200-3000 \mathrm{~kb}$. During PFGE, both the orientation and the duration of the electric field (the pulsed field) are periodically changed. The change in the electric field allows large DNA fragments to become re-orientated so that they can begin to migrate through the agarose pores. The PFGE patterns generated are highly specific for strains from a variety of species and detect polymorphic variation throughout the genome of the organism. This allows specific strain characterisation and consequently accurate assessment of their significance in connection with disease outbreaks $[11,22,29,30]$. 
PFGE is a highly reproducible and discriminating tool that characterises organisms by their molecular genotypes [13,31-33]. Bygraves and Maiden [30] used PFGE to subdivide serogroup A meningococcal MLEE electrophoretic types. PFGE has been used to characterise UK isolates of meningococci and demonstrated that there are two major clonal groups of group $\mathrm{C}$ meningococci which are prevalent in the UK and that some members of the larger clone have developed resistance to rifampicin $[11,34]$. The genomic diversity among serogroup $\mathrm{C}$ isolates was less than among serogroup $\mathrm{B}$ isolates $[11,22]$. PFGE has also been used to estimate the size of the $N$. meningitidis genome as $1.9 \pm 0.2 \mathrm{Mbp}$ (Nhe I fragments) or $2.3 \pm 0.2$ (SpeI fragments) [22], similar to earlier estimates of 1.8$2.0 \mathrm{Mbp}$ [30] and 2.3 Mbp [35].

PFGE generates simple genomic DNA restriction profiles without having to resort to probe hybridisation methods. It resolves DNA fragments $>40 \mathrm{~kb}$ which are unresolved by conventional electrophoresis. PFGE can be used to construct genomic physical maps [35] and is highly discriminatory. Discrimination is based on sequence variations. However, like other electrophoretic methods, it is not known what each fragment represents, i.e., the genetic basis of differences in band patterns is not known. The rapid PFGE [36] method adds improved response time to an accurate typing method, which is of fundamental importance for epidemiological investigations and therapeutic interventions in meningococcal outbreak situations. PFGE is suitable for typing both highly clonal (serogroup A) and less clonal (serogroups B and C) populations of $N$. meningitidis. PFGE identifies the micro-variation that is required to distinguish between strains circulating within a geographical location.

Limitations of PFGE include the use of expensive enzymes and reagents, extended isolation and restriction procedures of genomic DNA within agarose, and the duration of the procedure (5-7 days) [22]. However, the use of new generation PFGE systems and the rapid PFGE procedure [36] have rendered it a simple method for subtyping micro-organisms. In comparative studies of the molecular subtyping of $N$. meningitidis serogroup B by serotyping and serosubtyping, MLEE, ribotyping, PCR-restriction fragment length polymorphism (RFLP) of the internally transcribed spacer region of the rRNA operon and PFGE, PFGE showed the best discriminatory ability [37]. It was less costly than ribotyping [13].

\section{Gene-based methods}

Ribotyping or ribosomal DNA RFLP is a method that probes restriction fragments of genomic DNA with cloned probes that contain all or part of the $16 \mathrm{~S}$ and 23S rRNA genes. Patterns are easy to interpret because of a limited number of hybridised fragments, and the ribotypes are stable and reproducible after subculture of the same organism. Genes coding for rRNA are highly conserved and most bacteria have multiple ribosomal operons. Thus, probing permits inter-species and intraspecies discrimination [38,39].

In our own ribotyping studies meningococcal genomic DNA was isolated by a modified Pitcher's method $[22,26]$. After restriction digest, electrophoresis and transfer of DNA fragments to nylon matrix, the membrane was probed with ${ }^{32} \mathrm{P}$-labelled ribosomal $16+23 \mathrm{~S}$ rRNA from Escherichia coli $[13,26]$.

Genomic DNA of 94 isolates of $N$. meningitidis digested with $B g l$ II was ribotyped and the isolates were characterised into 13 groups, with the majority $(61 \%)$ placed in only two groups [26]. The discriminating capacity of ribotyping was improved when meningococcal DNA was digested with ClaI, EcoRI and Xho I and ribotyping showed a greater discriminatory ability than MLEE for subtyping $N$. meningitidis serogroup C [40]. In a comparison of five molecular typing methods for serogroup B strains, PFGE, MLEE and ribotyping showed $100 \%$ typability. However, Simpson's discrimination indices of diversity were lower for ribotyping at $98.8 \%$, with MLEE $99.4 \%$ and PFGE 99.7\% [37]. Nevertheless, ribotyping offers a good typing method; it is useful for long-term epidemiological studies with the employment of multiple restriction endonucleases providing additional discriminatory capacity. Ribotyping is a less costeffective method when compared with PFGE [13].

Other methods that employ cloned meningococcal fragments as probes have been described. Knight et al. [41] used a specific DNA probe (pUS210) which carried insert DNA (that is repeated in the meningococcal genome) to characterise serogroup B15/16 sulphonamide-resistant strains isolated in the UK between 1984 and 1989 that caused prolonged outbreaks in Gloucester and Plymouth. They concluded that the prolonged meningococcal disease in these two districts was due to a clonal population of virulent strains that were distinct from those obtained from elsewhere in the UK. Fox et al. [42] used a different probe (cloned fragment of an EcoRI digest from serogroup B15/16 sulphonamide-resistant) to characterise strains from the same outbreaks and demonstrated that the isolates from Gloucester and Plymouth were genetically distinct, although by MLEE they were of the same ET type.

\section{PCR-based methods}

A number of PCR-based techniques have been used for non-culture-based subtyping of meningococci from clinical specimens. These methods are simpler, faster and need much less DNA for analysis than culturebased genotyping methods. Generally, a known sequence is amplified directly from clinical specimens, digested with restriction endonucleases, and the frag- 
ments of DNA are compared (PCR-RFLP). The ultimate purpose of PCR-based DNA fingerprinting research is the construction of DNA fingerprint databanks which can be accessed by different laboratories for comparison with the fingerprints obtained for unknown isolates. Several PCR methods which are based on amplification of all or parts of a gene have been used to identify and type $N$. meningitidis (Table 1). Multiple arbitrary amplicon profiling (MAAP) or amplification fragment length polymorphism (AFLP), a group of related methods that include arbitrarily primed PCR (APPCR), [43, 44] random amplification of polymorphic DNA (RAPD-PCR) [45] and direct amplification fingerprinting (DAF) [46] involve randomly amplified segments of the target DNA with a single primer which has no known homology to the target sequence.

Cell membrane, ribosomal operons, resistance determinants and repetitive elements have been targeted for PCR-RFLP subtyping of $N$. meningitidis. PCR-RFLP of four cell membrane-associated genes has permitted identification or typing, or both, of $N$. meningitidis. Sequences of the pili genes have been used to design primers based on major pili subunit Pil A. PCR primers in the pilA/piIB locus were used to obtain an amplicon that was digested with three different enzymes and analysed. PilA is universally present as a stable gene in all meningococcal strains and contains hypervariable as well as conserved sequences. Thus the use of the pilA locus for PCR-restriction endonuclease patterns is advantageous [27, 47]. This method has the potential for both the identification and molecular typing of $N$. meningitidis $[27,47]$. One of the authors (D.E.Y.) obtained spurious minor amplicons along with fragments of the expected size when the pilA/piIB primer pair was used to type meningococci.

Sequence analysis of the sialyltransferase (siaD) genes of serogroup B and C meningococci [48] has permitted the design of PCR primers specific for serogroup B and $\mathrm{C}$ siaD genes. The siaD gene encodes a polysialyltransferase which is needed for the synthesis of capsular polysialic acid chains. The PCR assay has been adapted to an ELISA format. The serogroupspecific siaD PCR ELISA can be applied to non-culture diagnosis of meningococcal infection and outbreak investigations [49]. Vogel and colleagues [50] recently described a two-step siaD PCR which can distinguish between serogroup B, C, W135 and Y meningococci.

Meningococcal serosubtypes have been identified by por $A$ gene PCR. Primers are designed to amplify por $A$, and the amplicon is labelled and hybridised to reference DNA samples immobilised in an ordered array on a membrane filter [28]. Nested porA PCR was used to amplify and sequence target DNAs from a single cfu of $N$. meningitidis and from culture-negative cerebrospinal fluid (CSF) [51]. Again, a nested PCR amplification of por $B$ from CSF with subsequent hybridisation of the PCR products permitted diagnosis and typing directly from CSF [52].

Alterations within the meningococcal dhps gene confer sulphonamide resistance [53]. PCR primers based on sequence analysis of the dhps gene can be used for both detection [54] and typing [55] of meningococci. Detection rests on visualising an amplicon of desired size, and typing is achieved by Hha I amplification restriction endonuclease analysis (PCR-AREA).

PCR-ribotyping is another method for detecting and typing meningococci. Sequence analysis of bacterial ribosomal (r) DNA loci was used to design primer pairs which specifically detected $N$. meningitidis [56]. An amplicon of $600 \mathrm{bp}$ obtained from the $16 \mathrm{~S}-23 \mathrm{~S}$ internal transcribed spacer region of $N$. meningitidis has been digested with $A l u \mathrm{I}$ to generate restriction fragments which permit molecular typing [57].

Repetitive DNA sequences are universally present in eubacteria and have been applied to fingerprinting of bacterial genomes [58]. Repetitive element-based PCR (rep-PCR) was recently developed by Woods et al. [59] as a genotyping method for $N$. meningitidis. Although

Table 1. Targets used in PCR-RFLP/MAAP typing of $N$. meningitidis

\begin{tabular}{lllll}
\hline Targets & Typing method & Identification & Typing & Reference \\
\hline Cell membranes & & & & \\
PilA/pilB locus (pilus) & PCR-RFLP & Yes & Yes & {$[27,47]$} \\
SiaD gene serogroup- specific & PCR-RFLP & Yes & Yes & {$[48,49,50]$} \\
sialyltransferases & & & & \\
OMP1 (porA gene) & PCR-RFLP & Yes & Yes & {$[28,51]$} \\
VR1 of porA (PCR-SSCP) & PCR-RFLP & Yes & No & {$[62]$} \\
Class 2/3 OMP porB & PCR-RFLP & Yes & Yes & {$[52]$} \\
Ribosomal & & & & No \\
16S rRNA gene & PCR-RFLP & Yes & Yes & {$[56]$} \\
16S-23S intergenic spacer & PCR-RFLP & Yes & & \\
Resistance determinants & PCR-RFLP & Yes & Yes & {$[53,54,55]$} \\
Dhps gene & & & & \\
Repetitive element-based & PCR-RFLP & No & Yes & {$[59]$} \\
PCR (rep-PCR) & PCR-RFLP & Yes & No & {$[63]$} \\
IS 1106 (PCR ELISA) & MAAP-PCR & No & Yes & {$[67,68]$} \\
Arbitrarily primed PCR or RAPD & M &
\end{tabular}

RFLP, restriction fragment length polymorphism; MAAP, multiple arbitrary amplicon profiling. 
rep-PCR is rapid and genome-based [59], in the experience of one us (D.E.Y.), the method was less discriminatory than PFGE or MLEE. The insertion sequence IS1106 present in the meningococcal genome [60] has also been used as a PCR target for specific and sensitive detection of $N$. meningitidis DNA in CSF specimens [61] and in specimens of peripheral blood [62]. The IS1106-PCR has been adapted to a PCR ELISA format for the diagnosis of meningococcal infection $[63,64]$.

PCR combined with single-strand conformation polymorphism (PCR-SSCP) has been used to demonstrate the identity or non-identity of meningococcal strains present in clinical specimens obtained from different patients [65]. PCR-SSCP is capable of detecting a single nucleotide substitution due to a resulting alteration in the conformation of single-stranded DNA under non-denaturing conditions. Altered conformation affects the migration velocity of ssDNA, which is detected as a shift or the presence of new bands in a non-denaturing gel.

MAAP methods have a common strategy involving the PCR amplification of random genomic DNA fragments with single [43] or multiple [44] arbitrary primers. A characteristic pattern of amplification products is obtained with each primer and is visualised by ethidium bromide staining, silver staining or radionuclide incorporation. Of the MAAP methods, RAPD has proved to be an easy and most informative DNA-based method of typing bacteria. The technique is increasing in popularity because of its ability to detect polymorphism rapidly at a number of different loci with nanogram quantities of genomic DNA, and no genomic sequence or organism information is required. RAPD is capable of detecting single nucleotide insertions or deletions or substitutions. However, the use of internal controls and a high level of standardisation is necessary if RAPD results are to be reproducible [66].

Woods et al. [67] used RAPD to analyse disease and carrier strains of $N$. meningitidis isolated during a university outbreak in Connecticut. They concluded that RAPD was a sensitive and efficient method to determine genetic relatedness of the meningococcal strains and to facilitate epidemiological, clinical and population genetic studies. Bart and co-workers [68] have also shown that RAPD genotyping of serogroup A meningococci gave results comparable to those of MLEE and that RAPD results could be linked to previously characterised genotypes.

\section{Methods that index very slowly accumulating variations}

\section{$M L E E$}

MLEE is a typing method that determines the mobilities of a selection of constitutive metabolic enzymes in a starch gel or polyacrylamide gel matrix. Variations in the mobility of a constitutive enzyme for different strains of the same species under these conditions can be attributed to isozymes or allozymes. Changes in the mobility of enzymes are caused by charge differences due to amino acid substitutions in the polypeptide sequence. However, because its genetic basis is well understood, MLEE has been used widely over many years to determine genetic variation quantitatively [18]. MLEE only indexes the genotype indirectly. Each electrophoretic variant is assigned a number score and each unique combination of scores is called the electrophoretic type (ET).

In bacterial population genetics, natural populations are investigated extensively to understand their basic structures and evolution. MLEE and comparative nucleotide sequence analysis are two important methods for studying bacterial population genetics, and have shown that many species of pathogenic bacteria (e.g., salmonellae) are basically clonal, whereas other species (e.g., N. gonorrhoeae) are panmictic (show free recombination) [69]. It is unlikely that any bacterial species is exclusively clonal or panmictic and there is probably a spectrum of population structures between these two extremes.

MLEE was used to study the population genetics and epidemiology of $107 \mathrm{UK} N$. meningitidis isolates from carriers and clinical cases. They could be placed in 88 ETs. The genetic diversity of the population was estimated as 0.700 , with serogroup B showing a higher (0.707) degree of diversity than serogroup $C$ isolates (0.605) [70]. Certain strains within serogroups B and C appear to diversify more slowly than others and give rise to the hyper-endemic transient clones [71]. There was no relationship between the 88 ETs found among the 107 UK isolates and carriage or infection. Some ETs were isolated from both carriers and clinical cases, indicating that host rather than bacterial factors determined progression to disease [70].

As it reflects genetic changes which occur very slowly, MLEE is suitable for both long-term and global epidemiology. MLEE is a powerful technique which indexes the genotype indirectly and has been widely used to study genetic relationships among meningococci $[16,17,19,70]$. However, it is a labour-intensive and time-consuming technique. It requires pure cultures of strains [22].

\section{Multilocus sequence typing (MLST)}

Multilocus sequence typing extends the MLEE approach. It is based on direct sequencing of c. 470-bp PCR products of six housekeeping genes. By assigning arbitrary numbers for alleles on each locus, dendrograms can be constructed from the pairwise differences in multilocus allelic profiles by cluster analysis. 
Strain associations shown by MLST were consistent with clonal groups previously established by MLEE [72]. MLEE detects only those alleles with differences in coding sequences that lead to electrophoretic mobility changes, whereas with MLST direct assignment of alleles is based on nucleotide sequence differences. Thus the latter distinguishes more alleles per locus, permitting a higher level of discrimination between isolates.

Another advantage of MLST is that, unlike most restriction endonuclease methods, it permits comparison of results from different laboratories without the need to exchange strains or to take variations in electrophoretic techniques into account. Therefore, it is well suited to the construction of global databanks which can be accessed by different laboratories for comparison of results. Meningococci can now be assigned to global clonal groups in an ever-expanding central database $[50,72]$. Although MLST could well become the 'gold standard' method for study of the long-term evolution and global epidemiology of meningococci, it is insensitive to micro-evolution. Thus, typing methods such as PFGE that are very sensitive to micro-evolution will continue to be used to reveal minor differences between related strains [73].

\section{Non-culture-based diagnosis of $N$. meningitidis in clinical specimens}

Because of the often rapid and dramatic development of systemic meningococcal disease, it is recommended that antibiotic treatment begins as soon as a clinical diagnosis is suspected and before laboratory tests are initiated. This results in a significant lowering of the proportion of suspected systemic cases confirmed by culture. Lumbar puncture is also being done less frequently - it is not a risk-free procedure.

Several PCR-based methods have been described for the detection of meningococcal DNA in clinical specimens (see references in Table 1). The siaD PCR has been used in several meningococcal outbreak investigations recently in the UK. When adapted to an ELISA format incorporating hybridisation with serogroup-specific $\mathrm{B}$ and $\mathrm{C}$ oligonucleotide probes, the specificity for CSF was $100 \%$ and sensitivities were $81 \%$ for CSF, $63 \%$ for whole blood and $30 \%$ for serum [49]. The development of a two-step version of siaD PCR [50] able to distinguish between serogroup B, C, W135 and Y meningococci will enhance the utility of this method for the detection of meningococci in clinical specimens. Mammen et al. [74] have also reported confirmation of meningococcal infection with a diagnostic nested PCR for porA in urine. An evaluation in England of PCR-based methods which detected IS $1106[60,61]$, class $2 / 3$ OMPs (porB [50]) and siaD genes [49] for diagnosis of meningococcal infections gave a $20 \%$ increase in laboratory-ascer- tained infection [64]. Variable regions within porB encode the class 2 and class 3 proteins and several probes based on these variable regions have been used to identify all the major meningococcal serotypes. The nested PCR amplification of porB from CSF with subsequent hybridisation of the PCR products permits both diagnosis and typing information to be obtained directly from the CSF sample. The epidemiological information on individual variable region genotypes given by this method may aid in the selection of strains for vaccine development and in the analysis of culturenegative suspected cases [52]. Other methods such as porB PCR-ELISA [75] and variable region 1 of porA (PCR-SSCP) [65] have been applied to meningococcal diagnosis in clinical specimens. The application of these PCR-based methods will provide rapid diagnosis, may be important for disease surveillance in culturenegative specimens, will improve case ascertainment and confirm sources of active transmission [62]. Such tests need further evaluation.

\section{Sequence analysis}

DNA sequencing remains the most sensitive method of detecting polymorphism within a gene. Full genome sequences can be used to identify previously unrecognised elements as possible targets for epidemiological studies, such as novel transposons, insertion elements and repetitive DNA. Comparison of genome sequences as a way of typing is not currently feasible in most laboratories. Sequencing methods need to be simplified and automated and then appropriate genomic targets of interest must be identified and their sequence variability determined. This constitutes an enormous task that requires national and international collaborations. However, as discussed above, MLST offers a feasible approach to selective sequence analysis as a method for characterising meningococci.

With the completion of genome sequence programmes, DNA-chip-based detection systems based on them will provide novel typing strategies [76] that may be useful in the diagnosis and typing of $N$. meningitidis. Sequence analysis of the 16S rRNA from different species has proved a useful and rapid discriminatory tool both among and within genera. It has been used to study bacterial evolution [77] and phylogenetic relationships among some members of the genera Neisseria, Acinetobacter, Moraxella and Kingella [78]. The clonal relationship of recent UK isolates of serogroup C meningococci was determined [22,34] and 12 PFGE and $11 S t u$ I REA clonal groups were identified. The 11 Stu I REA clonal groups were further analysed by sequencing their $16 \mathrm{~S}$ rRNA gene: $750 \mathrm{bp}$ from the $5^{\prime}$ end of the 16S rRNA gene for a representative strain from each of the 11 StuI REA clones were sequenced and the results were compared with those of the StuI REA to further assess the genetic relatedness of the UK serogroup C isolates. All sequences from the same $S t u \mathbf{I}$ 
REA clone were identical. There were differences within the 16S rRNA gene of $N$. meningitidis, which suggests that mutations within the gene have occurred as the organisms have evolved. A comparison between REA and $16 \mathrm{~S}$ sequencing showed that sequence differences occurred between clones and not within clones, suggesting that a degree of clonality exists within the population structure of serogroup $\mathrm{C} N$. meningitidis [79].

\section{Conclusions}

The population structure of $N$. meningitidis is complex, with the rate of its diversification varying considerably. Serogroup A strains diversify slowly with their clonal population structure persisting for long periods. Thus for serogroup A strains, ribotyping, PFGE, RAPD or MLEE can each provide a consistent measure of the relationships between strains. However, for serogroups $\mathrm{B}$ and $\mathrm{C}$ meningococci, which diversify relatively rapidly, PFGE, ribotyping, RAPD, MLEE and other PCR-based methods can be applied in localised outbreaks. Quantitative methods (e.g., MLEE and MLST) are necessary if an evaluation of long-term or global epidemiology of meningococci is required.

A range of molecular typing techniques is available to assist investigations into meningococcal epidemiology. They vary in utility for determining genetic relatedness among strains. Currently, molecular typing of $N$. meningitidis remains in a state of flux. We prefer those methods for which the genetic basis is fully understood. As new methods are developed, we believe that they should be based on strategies that permit direct or indirect comparison with sequence information. With the completion of $N$. meningitidis genome sequencing programmes, DNA-chip-based detection systems based on the sequence information will provide such typing strategies.

In the meantime, PCR-based methods used for the detection and typing of meningococcal DNA from clinical specimens show good potential. PFGE and other PCR-based methods are useful for identifying micro-variations necessary to distinguish between strains circulating within a geographical location. MLST may well become the standard method for studying bacterial populations, examining their evolutionary genetics and long-term or global epidemiology.

\section{References}

1. Peltola H. Meningococcal disease still with us. Rev Infect Dis 1983; 5: 71-91.

2. World Health Organization. Epidemiological surveillance and control of cerebrospinal meningitis in Africa. WHO Chron 1973; 27: 347-351.

3. Verheul AF, Snippe H, Poolman JT. Meningococcal lipopolysaccharides: virulence factor and potential vaccine component. Microbiol Rev 1993; 57: 34-49.
4. Brandtzaeg P. Systemic meningococcal disease: clinical pictures and pathophysiological background. Rev Med Microbiol 1996; 7: 63-72.

5. Abdullahi H, Poolman JT. Whole-cell ELISA for typing Neisseria meningitidis with monoclonal antibodies. FEMS Microbiol Lett 1987; 48: 367-371.

6. Branham SE. Serological relationships among meningococci. Bacteriol Rev 1953; 17: 175-188.

7. Frasch CE. Development of meningococcal serotyping. In: Vedros NA (ed) Evolution of meningococcal disease, 2nd edn. Boca Raton, FL, CRC Press. 1987: 39-55.

8. Frasch CE, Zollinger WD, Poolman JT. Serotype antigens of Neisseria meningitidis and a proposed scheme for designation of serotypes. Rev Infect Dis 1985; 7: 504-510.

9. Craven DE, Frasch CE, Robbins JB, Feldman HA. Serogroup identification of Neisseria meningitidis: comparison of an antiserum agar method with bacterial slide agglutination. $J$ Clin Microbiol 1978; 7: 410-414.

10. Vedros NA. Serology of the meningococcus. In: Bergan $T$, Norris JR (eds) Methods in microbiology. London, Academic Press. 1978: 293-314.

11. Yakubu DE, Pennington TH. Epidemiological evaluation of Neisseria meningitidis serogroup B by pulsed-field gel electrophoresis. FEMS Immunol Med Microbiol 1995; 10: 185-189.

12. Maiden MCJ, Feavers IM. Meningococcal typing. $J$ Med Microbiol 1994; 40: 157-158.

13. Swaminathan B, Matar GM. Molecular typing methods. In: Persing DH, Smith TF, Tenover FC, White TJ (eds) Diagnostic molecular microbiology: Principles and applications. Washington, DC, American Society for Microbiology. 1993: 26-50.

14. Hunter PR, Gaston MA. Numerical index of the discriminatory ability of typing systems: an application of Simpson's index of diversity. J Clin Microbiol 1988; 26: 2465-2466.

15. Greenwood BM. Meningococcal infections. In: Weatherall DJ et al. (eds) Oxford textbook of medicine. Oxford, Oxford University Press. 1996: 533-544.

16. Caugant DA, Frøholm LO, Bøvre $\mathrm{K}$ et al. Intercontinental spread of a genetically distinctive complex of clones of Neisseria meningitidis causing epidemic disease. Proc Natl Acad Sci USA 1986; 83: 4927-4931.

17. Caugant DA, Mocca LF, Frasch CE, Frøhølm LO, Zollinger WD, Selander RK. Genetic structure of Neisseria meningitidis populations in relation to serogroup, serotype, and outer membrane protein pattern. J Bacteriol 1987; 169: 2781-2792.

18. Selander RK, Caugant DA, Ochman H, Musser JM, Gilmour $\mathrm{MN}$, Whittam TS. Methods of multilocus enzyme electrophoresis for bacterial population genetics and systematics. Appl Envir Microbiol 1986; 51: 873-884.

19. Olyhoek T, Crowe BA, Achtman M. Clonal population structure of Neisseria meningitidis serogroup A isolated from epidemics and pandemics between 1915 and 1983. Rev Infect Dis 1987; 9: 665-692.

20. Achtman M. Clonal spread of serogroup A meningococci: a paradigm for the analysis of microevolution in bacteria. Mol Microbiol 1994; 11: 15-22.

21. Maynard Smith J, Smith NH, O’Rourke M, Spratt BG. How clonal are bacteria? Proc Natl Acad Sci USA 1993; 90: 4384-4388.

22. Yakubu DE, Abadi FJR, Pennington TH. Molecular epidemiology of recent United Kingdom isolates of Neisseria meningitidis serogroup C. Epidemiol Infect 1994; 113: 53-65.

23. Bjorvatn B, Lund V, Kristiansen B-E, Korsnes L, Spanne O, Lindqvist B. Application of restriction endonuclease fingerprinting of chromosomal DNA of Neisseria meningitidis. $J$ Clin Microbiol 1984; 19: 763-765

24. Bjorvatn B, Hassan-King M, Greenwood B, Haimanot RT, Fekade D, Sperber G. DNA fingerprinting in the epidemiology of African serogroup A Neisseria meningitidis. Scand $J$ Infect Dis 1992; 24: 323-332.

25. Crowe BA, Wall RA, Kusecek B et al. Clonal and variable properties of Neisseria meningitidis isolated from cases and carriers during and after an epidemic in The Gambia, West Africa. $J$ Infect Dis 1989; 159: 686-700.

26. Jordens JZ, Pennington TH. Characterization of Neisseria meningitidis isolates by ribosomal RNA gene restriction patterns and restriction endonuclease digestion of chromosomal DNA. Epidemiol Infect 1991; 107: 253-262.

27. Giorgini D, Taha M-K. Molecular typing of Neisseria meningitidis serogroup A using the polymerase chain reaction 
and restriction endonuclease pattern analysis. Mol Cell Probes 1995; 9: 297-306.

28. Maiden MCJ, Bygraves JA, McCarvil J, Feavers IM. Identification of meningococcal serosubtypes by polmerase chain reaction. $J$ Clin Microbiol 1992; 30: 2835-2841.

29. Arbeit RD, Arthur M, Dunn R, Kim C, Selander RK, Goldstein $\mathrm{R}$. Resolution of recent evolutionary divergence among Escherichia coli from related lineages: the application of pulsed field electrophoresis to molecular epidemiology. J Infect Dis 1990; 161: 230-235.

30. Bygraves JA, Maiden MCJ. Analysis of the clonal relationships between strains of Neisseria meningitidis by pulsed field gel electrophoresis. J Gen Microbiol 1992; 138: 523-531.

31. Birren BW, Lai E. Pulsed field gel electrophoresis: a practica guide. San Diego, CA, Academic Press. 1993.

32. Maslow JN, Slutsky AM, Arbeit RD. Application of pulsed field gel electrophoresis to molecular epidemiology. In: Persing $\mathrm{DH}$, Smith TF, Tenover FC, White TJ (eds) Diagnostic molecular microbiology: principles and applications. Washing ton, DC, American Society for Microbiology. 1993: 563-572.

33. Tenover $\mathrm{FC}$, Arbeit $\mathrm{RD}$, Goering $\mathrm{RV}$ et al. Interpreting chromosomal DNA restriction patterns produced by pulsedfield gel electrophoresis: criteria for bacterial strain typing. $J$ Clin Microbiol 1995; 33: 2233-2239.

34. Carter PE, Abadi FJR, Yakubu DE, Pennington TH. Molecular characterization of rifampicin-resistant Neisseria meningitidis. Antimicrob Agents Chemother 1994; 38: 1256-1261.

35. Bautsch W. A NheI macrorestriction map of the Neisseria meningitidis B1940 genome. FEMS Microbiol Lett 1993; 107; 191-198.

36. Gautom RK. Rapid pulsed-field gel electrophoresis protocol for typing of Escherichia coli 0157:H7 and other Gram-negative organisms in 1 day. J Clin Microbiol 1997; 35: 2977-2980.

37. Swaminathan B, Matar GM, Reeves MW et al. Molecular subtyping of Neisseria meningitidis serogroup B: comparison of five methods. J Clin Microbiol 1996; 34: 1468-1473.

38. Grimont F, Grimont PAD. DNA fingerprinting. In: Stackebrandt E, Goodfellow M (eds) Nucleic acid techniques in bacterial systematics. (Modern Microbiological Methods Series.) Chichester, John Wiley and Sons. 1991: 249-280.

39. Stull TL, LiPuma JJ, Edlind TD. A broad-spectrum probe for molecular epidemiology of bacteria: ribosomal RNA. $J$ Infect Dis 1988; 157: 280-286.

40. Woods TC, Helsel LO, Swaminathan B et al. Characterization of Neisseria meningitidis serogroup $\mathrm{C}$ by multilocus enzyme electrophoresis and ribosomal DNA restriction profiles (ribotyping). J Clin Microbiol 1992; 30: 132-137.

41. Knight AI, Cartwright KV, McFadden J. Identification of a UK outbreak strain of Neisseria meningitidis with a DNA probe. Lancet 1990; 335: 1182-1184.

42. Fox AJ, Jones DM, Gray SJ, Caugant DA, Saunders NA. An epidemiologically valuable typing method for Neisserio meningitidis by analysis of restriction fragment length polymorphisms. J Med Microbiol 1991; 34: 265-270.

43. Welsh J, McClelland M. Fingerprinting genomes using PCR with arbitrary primers. Nucleic Acids Res 1990; 18 7213-7218

44. Welsh J, McClelland M. Genomic fingerprinting using arbitrary primed PCR and a matrix or pairwise combinations of primers. Nucleic Acids Res 1991; 19: 5275-5279.

45. Williams JGK, Kubelik AR, Livak KJ, Rafalski JA, Tingey SV DNA polymorphisms amplified by arbitrary primers are useful as genetic markers. Nucleic Acids Res 1990; 18: 6531-6535.

46. Bassam BJ, Caetano-Anolles G, Gresshoff PM. DNA amplification fingerprinting of bacteria. Appl Microbiol Biotechnol 1992; 38: $70-76$.

47. Guibourdenche $M$, Giorgini D, Guèye A, Larribe M, Riou J-Y, Taha M-K. Genetic analysis of a meningococcal population based on polymorphism of the pilA-pilB locus: a molecular approach for meningococcal epidemiology. J Clin Microbiol 1997; 35: 745-750.

48. Frosch M, Edwards U, Bousset K, Krauße B, Weisgerber C. Evidence for a common molecular origin of the capsule gene loci in gram-negative bacteria expressing group II capsular polysaccharides. Mol Microbiol 1991; 5: 1251-1263.

49. Borrow $\mathrm{R}$, Claus $\mathrm{H}$, Guiver $\mathrm{M}$ et al. Non-culture diagnosis and serogroup determination of meningococcal $\mathrm{B}$ and $\mathrm{C}$ infection by a sialyltransferase (siaD) PCR ELISA. In: Zollinger WD, Frasch CE, Deal CD (eds) Proceedings of the Tenth
International Pathogenic Neisseria Conference, Baltimore USA, 1996: 439-440.

50. Vogel U, Morelli G, Zurth $\mathrm{K}$ et al. Necessity of molecular techniques to distinguish between Neisseria meningitidis strains isolated from patients with meningococcal disease and from their healthy contacts. J Clin Microbiol 1998; 36: 2465-2470.

51. Saunders NB, Zollinger WD, Rao VB. A rapid and sensitive PCR strategy employed for amplification and sequencing of porA from a single colony-forming unit of Neisseria meningitidis. Gene 1993; 137: 153-162.

52. Bash M, Barroso DE, Frasch CE. Identification and typing of Neisseria meningitidis por $B$ from cerebrospinal fluid using nested PCR and biotin labeled probe hybridization. In: Zollinger WD, Frasch CE, Deal CD (eds) Proceedings of the Tenth International Pathogenic Neisseria Conference, Baltimore, USA, 1996: 417-418.

53. Rådström $\mathrm{P}$, Fermér $\mathrm{C}$, Kristiansen $\mathrm{B}-\mathrm{E}$, Jenkins $\mathrm{A}$, Sköld $\mathrm{O}$ Swedberg G. Transformational exchanges in the dihydropteroate synthase gene of Neisseria meningitidis: a novel mechanism for acquisition of sulfonamide resistance. $J$ Bacterio 1992; 174: 6386-6393.

54. Kristiansen B-E, Ask E, Jenkins A, Fermér C, Rådström $P$ Sköld O. Rapid diagnosis of meningococcal meningitis by polymerase chain reaction. Lancet 1991; 337: 1568-1569.

55. Kristiansen B-E, Fermér C, Jenkins A, Ask E, Swedberg G, Sköld O. PCR amplicon restriction endonuclease analysis of the chromosomal dhps gene of Neisseria meningitidis: a method for studying spread of the disease-causing strain in contacts of patients with meningococcal disease. $J$ Clin Microbiol 1995; 33: 1174-1179.

56. Olcén P, Lantz P-G, Bäckman A, Rådström P. Rapid diagnosis of bacterial meningitis by a seminested PCR strategy. Scand $J$ Infect Dis 1995; 27: 537-539.

57. McLaughlin GL, Howe DK, Biggs DR et al. Amplification of rDNA loci to detect and type Neisseria meningitidis and other eubacteria. Mol Cell Probes 1993; 7: 7-17.

58. Versalovic J, Koeuth T, Lupski JR. Distribution of repetitive DNA sequences in eubacteria and application to fingerprinting of bacterial genomes. Nucleic Acids Res 1991: 19: 6823-6831.

59. Woods CR, Koeuth T, Estabrook MM, Lupski JR. Rapid determination of outbreak-related strains of Neisseria meningitidis by repetitive element-based polymerase chain reaction genotyping. J Infect Dis 1996; 174: 760-767.

60. Knight $\mathrm{AI}, \mathrm{Ni} \mathrm{H}$, Cartwright $\mathrm{KAV}$, McFadden JJ. Isolation and characterization of a novel insertion sequence, IS1106, downstream of the porA gene in B15 Neisseria meningitidis. Mol Microbiol 1992; 6: 1565-1573.

61. Ni H, Knight AI, Cartwright $\mathrm{K}$, Palmer WH, McFadden J. Polymerase chain reaction for diagnosis of meningococcal meningitis. Lancet 1992; 340: 1432-1434

62. Newcombe J, Cartwright K, Palmer WH, McFadden J. PCR of blood peripheral for diagnosis of meningococcal disease. $J$ Clin Microbiol 1996; 34:1637-1640.

63. Davison E, Borrow R, Guiver M, Kaczmarski EB, Fox AJ. The adaptation of the IS1106 PCR to a PCR ELISA format for the diagnosis of meningococcal infection. Serodiagn Immunother Infect Dis 1996; 8: 51-56.

64. Kaczmarski EB, Borrow $\mathrm{R}$, Gray SJ et al. Optimizing ascertainment of meningococcal infection in England and Wales - impact of novel diagnostic techniques and reconciliation of available datasets between the national reference laboratory and other surveillance schemes. In: Zollinger WD Frasch CE, Deal CD (eds) Proceedings of the Tenth International Pathogenic Neisseria Conference, Baltimore, USA, 1996: 475-476.

65. Newcombe J, Cartwright KAV, Palmer WH, McFadden J. PCR SSCP of clinical specimens for non-culture-based sub-typing of the meningococcus in clinical specimens. In: Zollinger WD Frasch CE, Deal CD (eds) Proceedings of the Tenth International Pathogenic Neisseria Conference, Baltimore, USA, 1996: 498-499.

66. Ellsworth DL, Rittenhouse KD, Honeycutt RL. Artifactua variation in randomly amplified polymorphic DNA banding patterns. Biotechniques 1993; 14: 214-217.

67. Woods JP, Kersulyte D, Tolan RW, Berg CM, Berg DE. Use of arbitrarily primed polymerase chain reaction analysis to type disease and carrier strains of Neisseria meningitidis isolated during a university outbreak. J Infect Dis 1994; 169 
$1384-1389$.

68. Bart A, Schuurman I, Achtman M, Caugant DA, Dankert J, van der Ende A. Random amplified polymorphic DNA (RAPD) genotyping of serogroup A meningococci yields results comparable to those of multilocus enzyme electrophoresis (MEE). In: Zollinger WD, Frasch CE, Deal CD (eds) Proceedings of the Tenth International Pathogenic Neisseria Conference, Baltimore, USA, 1996: 448.

69. Selander RK, Lia J, Boyd EF, Wang F-S, Nelson K. DNA sequence analysis of the genetic structure of populations of Salmonella enterica and Escherichia coli. In: Priest FG, Ramos-Cormenzana A, Tindall BJ (eds) Bacterial diversity and systematics. New York, Plenum Press. 1994: 17-49.

70. Abadi FJR. Population genetic and epidemiological studies of Neisseria meningitidis. $\mathrm{PhD}$ thesis, University of Aberdeen, 1996.

71. Maiden MCJ, Feavers IM. Population genetics and global epidemiology of the human pathogen Neisseria meningitidis. In: Baumberg S, Young JPW, Wellington EMH, Saunders JR (eds) Population genetics of bacteria. Society symposia No. 52. Cambridge, Cambridge University Press. 1995: 269-293.

72. Maiden MCJ, Bygraves JA, Feil E et al. Multilocus sequence typing: a portable approach to the identification of clones within populations of pathogenic microorganisms. Proc Natl Acad Sci USA 1998; 95: 3140-3145.

73. Morelli G, Malorny B, Muller K et al. Clonal descent and microevolution of Neisseria meningitidis during thirty years of epidemic spread. Mol Microbiol 1997; 25: 1047-1064.
74. Mammen MP, Saunder NB, Burgess JT, Smith JI, Warren RI, Zollinger WD. Confirmation of meningococcal sepsis using diagnostic nPCR of urine sample - a case report. In: Zollinger WD, Frasch CE, Deal CD (eds) Proceedings of the Tenth International Pathogenic Neisseria Conference, Baltimore, USA, 1996: 494-495.

75. Urwin R, Maiden MCJ, Feavers IM, Kriz P, Fox AJ. The molecular epidemiology of the porB gene of Neisseria meningitidis isolated in England and Wales. In: Zollinger WD, Frasch CE, Deal CD (eds) Proceedings of the Tenth International Pathogenic Neisseria Conference, Baltimore, USA, 1996: 494-495.

76. van Belkum A. Whole genome-sequencing and DNA-chips: implications for medical-microbiological epidemiologists. In Proceedings of the Fourth International Meeting on Bacterial Epidemiological Markers, Elsinore, Denmark, 1997: 4-8.

77. Woese CR. Bacterial evolution. Microbiol Rev 1987; 51: 221-271.

78. Enright MC, Carter PE, MacLean IA, McKenzie H. Phylogenetic relationships between some members of the genera Neisseria, Acinetobacter, Moraxella and Kingella based on partial $16 \mathrm{~S}$ ribosomal DNA sequence analysis. Int $J$ Syst Bacteriol 1994; 44: 387-891.

79. Carter PE, Abadi FJR, Pennington TH. Clonal analysis of Neisseria meningitidis: sequence studies on the $16 \mathrm{~S}$ ribosomal RNA. In: Zollinger WD, Frasch CE, Deal CD (eds) Proceedings of thgs of the Tenth International Pathogenic Neisseria Conference, Baltimore, USA, 1996: 425-426. 